\title{
Antigen testing and non-infectious shedding of SARS-COV-2
}

\author{
Yehuda Raveh $^{1}\left[\right.$ Jacques Simkins ${ }^{2}\left[\right.$. Ramona Nicolau-Raducu ${ }^{1}([)$
}

Received: 20 November 2020 / Accepted: 18 January 2021 / Published online: 10 February 2021

(c) Springer-Verlag GmbH, DE part of Springer Nature 2021

\section{Dear Editor,}

We read with great interest the article by Lanser et al. who studied the sensitivity of rapid antigen testing for SARS$\mathrm{CoV}-2$ in relation to the cycle threshold $(\mathrm{Ct})$ - a semiquantitative surrogate of viral load obtained by real-time polymerase chain reaction (RT-PCR) [1]. The authors considered a $\mathrm{Ct}>33$ to be indicative of non-infectious shedding, based on unpublished CDC figure data (dated July 22nd) depicting a $\mathrm{Ct}>33$ as cut-off for non-replicable virus in cell culture. The authors found low number $(16.7 \%)$ of positive antigen results in subjects with $\mathrm{Ct}$ value $>33$, and therefore concluded that a negative antigen result in previously positive subjects could be leveraged "to determine the time point when they are no longer contagious".

We would like to highlight serious limitations of Lanser et al.'s findings and conclusions. First, a statistical comparison of the antigen test results for subjects with $\mathrm{Ct}$ above or below 33 is not reported. Second, SARS-Cov-2 Ct values vary considerably between and within platforms, laboratories, and target genes [2]. The quoted CDC data pertain to the $\mathrm{N} 1-\mathrm{N} 3$ genes, while the study's cobas ${ }^{\circledR}$ platforms targets the ORF1-gene. Using the Applied Biosystems 7500 FAST system that targets the ORF1-gene, Ladhani et al. found a $\mathrm{Ct}>35$ as the cut-off for uncultivable virus [3]. Moreover, the CDC omitted any allusion to the aforementioned data in its October 19th update. Third, while RT-PCR is a highly sensitive method, its sensitivity for SARS-CoV-2 is only $\sim 70 \%$, and experts recommend at least two negative swabs prior to ruling out SAST-Cov-2 infection [4]. The authors did not provide any data regarding antigen test results in patients with negative RT-PCR swabs. These data

Yehuda Raveh

yraveh@miami.edu

1 Department of Anesthesia, Jackson Memorial Hospital, University of Miami, Miami, FL, USA

2 Division of Infectious Diseases, Department of Medicine, Miami Transplant Institute, University of Miami School of Medicine, Miami, FL, USA are essential to accurately determine the sensitivity and specificity of the antigen test, assess a plausible correlation between antigen test results and $\mathrm{Ct}$, and correctly inform infection control and public health policies. By limiting antigen testing to hospitalized RT-PCR positive subjects alone, the authors most likely overestimated the true sensitivity of the antigen assay, and were unable to estimate its specificity. Lastly, ample data suggest that $\mathrm{Ct}$ values should be interpreted in the clinical context of symptom-onset to test time-interval, as well as illness severity [5-7]. Since all the samples were obtained from hospitalized COVID19 patients, the study findings are strongly biased toward severe illness, and may not equally apply to public screening as proposed by the authors. Furthermore and as acknowledged by the authors, for a given $\mathrm{Ct}$ value-infectivity is much more probable when a swab is obtained at the onset of symptoms, rather than when taken 10 days later. Yet, the authors provided no data regarding the days from onset of symptoms to testing, and they grouped $\mathrm{Ct}$ values irrespective of this clinically important variable. While we agree with the authors that "antigen tests... might be suitable and effective for rapidly identifying infectious subjects with symptoms compatible to a COVID-19 infection", studies addressing these limitations will further support the wide-spread implementation of antigen tests.

We agree with the authors that a rapid test with a high sensitivity and specificity for SARS-CoV-2 infection and infectivity would benefit public and occupational health policies, as well as and infection control guidelines.

\section{Compliance with ethical standards}

Conflict of interest The authors declare that they have no conflict of interest.

\section{References}

1. Lanser L, Bellmann-Weiler R, Öttl K-W, et al. Evaluating the clinical utility and sensitivity of SARS-CoV-2 antigen testing 
in relation to RT-PCR Ct values. Infection. 2020. https://doi. org/10.1007/s15010-020-01542-0.

2. Rhoads D, Peaper DR, She RC, Nolte FS, Wojewoda CM, Anderson NW, et al. College of American Pathologists (CAP) microbiology committee perspective: caution must be used in interpreting the cycle threshold (Ct) value. Clin Infect Dis. 2020. https://doi. org/10.1093/cid/ciaa1199.

3. Ladhani SN, Chow JY, Janarthanan R, et al. Investigation of SARS-CoV-2 outbreaks in six care homes in London, April 2020. EClin Med. 2020;26:100533.

4. American Society of Transplantation. 2019-nCoV (Coronavirus): FAQs for organ transplantation. https://www.myast.org/sites/defau
1t/files/COVID19\%20FAQ\%20Tx\%20Centers\%2010.26.2020.pdf. Accessed 11 Aug 2020

5. Young BE, Ong SWX, Ng LFP, et al. Viral dynamics and immune correlates of COVID-19 disease severity. Clin Infect Dis. 2020. https://doi.org/10.1093/cid/ciaa1280.

6. Jefferson T, Spencer E, Brassey J, Heneghan C. Viral cultures for COVID-19 infectivity assessment. Systematic review. medRxiv 2020: 2020.08.04.20167932.

7. Folgueira MD, Luczkowiak J, Lasala F, Perez-Rivilla A, Delgado R. Persistent SARS-CoV-2 replication in severe COVID-19. medRxiv 2020: 2020.06.10.20127837. 